International Journal of Recent Advances in Mechanical Engineering (IJMECH) Vol.7, No.3, August 2018

\title{
Influence of Process Parameters on Performance of Wire EDM By Multi- OBJECTIVE GENETIC AlgORITHM
}

\author{
Gajanand Rathore ${ }^{1}$ and Amber Batwara ${ }^{2}$ \\ ${ }^{1,2}$ Department of Mechanical Engineering, Poornima College of Engineering, Jaipur, \\ 302022.
}

\begin{abstract}
Wire EDM machines are developed to cut any type of material which have soft to hard behavior in present era. Material must have conductive in nature for this type of machine operation like metals, alloys etc. Wire EDM machine can cut complex design as well as simple design of cut by its nature, sometime very complex cut designs are also easily cut by this machine.
\end{abstract}

The steady nature of parts being machined in wire electrical release machining is troublesome in light of the fact that the procedure parameters can't be controlled successfully. These are the greatest difficulties for the scientists and engineers. Producers endeavour to discover control variables to enhance the machining quality in view of their operational encounters, manuals or fizzled endeavours. Keeping in see the uses of material modern industrial steel (medium carbon steel), it has been chosen and has been machined on wire-cut EDM (Maxicut-e) of Electronica Machine Tools Limited. All experiments are carried out in CIPET, Jaipur.

The target of the present work was to explore the impacts of the different WEDM process parameters on the machining quality and to acquire the ideal arrangements of process parameters with the goal that the nature of machined parts can be streamlined. The whole arrangement of investigations was done in a staged way. The analyses in each stage were rehashed three times. The Taguchi system has been utilized to explore the impacts of the WEDM procedure parameters and in this manner to foresee sets of ideal parameters for ideal quality attributes. The response surface approach (RSM) in conjunction with single piece and focus point configuration has been utilized to build up the observational models for reaction qualities. Development of mathematical models for cutting rate and cutting time using response surface methodology. MOGA optimization technique was also applied in this study for analysis and prediction of results.

\section{KEYWORDS}

Wire EDM machine, DOE technique, RSM method, Modal equation, MOGA

\section{INTRODUCTION}

Now days the industries uses non-conventional machining method like electric, chemical, sound, light which are helpful to machine the hard component and convert them into complicate shape. The machining processes are non-conventional in the sense that instead of using traditional tools for machining, some form of energy is used. The problem of high complexity in shape, size and higher demand for of accuracy and surface finish can be solved by non-conventional machining.[4]

EDM is a machining technology which is today one of the state of the art machining processed for metals. EDM is a controlled metal removal process that is used to remove metal by means of electric spark erosion. When electric current is supply, a spark is generated between the work piece and the electrode creating high temperature which causes erosion on the surface of work piece as well as on the electrode. The temperature is controlled by regulating the spark gap between the electrode and the work piece. Figure 1 is shown the setup of the wire EDM. The tool 
is made cathode and work piece is anode. The electrode and work piece should have good electrical conductivity to generate the good spark. The material removal rate (MRR) and surface finish are controlled by the frequency and the spark intensity. A thin gap is maintained between the tool and work piece. Both tool and work piece are submerged in a dielectric fluid. Deionised water, kerosene and EDM oil are very common type of dielectric used in EDM machining process

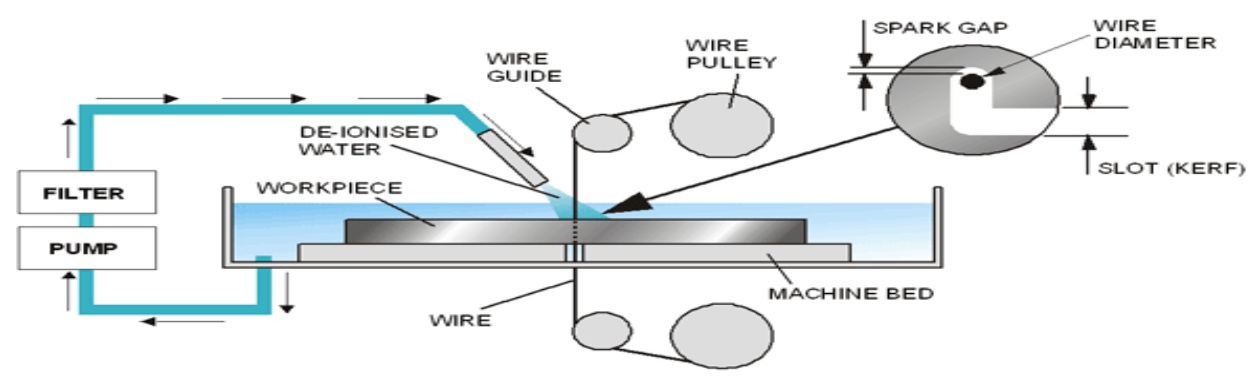

Figure 1. Working principle of wire EDM [5]

\section{EXPERIMENTAL WORK}

The working input parameters for current study was looked over past research work, yet machine factors were additionally consider in this research examination work. Straight forward rectangular cut was decided for cut utilizing wire EDM machine. Every specialized determination of machine with constraints was considered in this section. Machine which was utilized for this examination was Maxicut-e WEDM (see figure 3). Modern variant of steel was decided for this research examination work. The machine was introduced in CIPET, Jaipur. The essential execution measures in WEDM are cutting time and cutting rate. In WEDM operations, cutting rate decides the financial aspects of machining and rate of creation though over cut means level of exactness and dimensional precision.

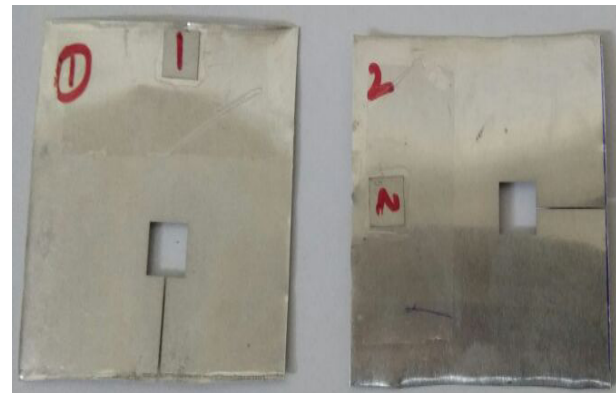

Figure 2. Design of Cut

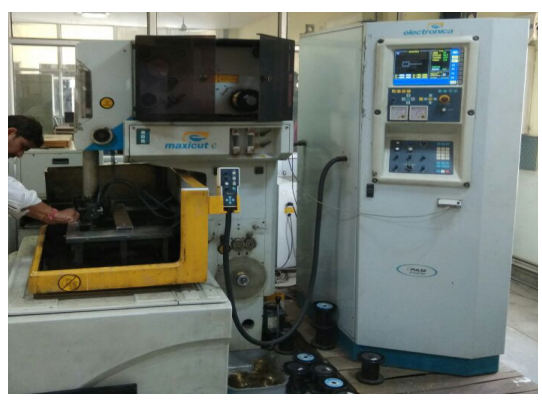

Figure 3. WEDM installed at CIEPT Jaipur

The modern steel sheet of $75 \mathrm{~mm} \times 75 \mathrm{~mm} \times 0.75 \mathrm{~mm}$ size has been utilized as a work piece material for the present analyses. This modern industrial steel is normally hot-worked industrial steel with moderate hardness and sturdiness properties. Chemical composition of industrial steel is carbon $0.20 \%, \mathrm{Mn} 0.45 \%$ and others $0.15 \%$.

\section{DESIGN OF EXPERIMENT AND RESEARCH METHODOLOGY}

Every work has fixed research methodology for completion of work with good effort and quality of data. Flow diagram presents the research methodology of this work in detail. 


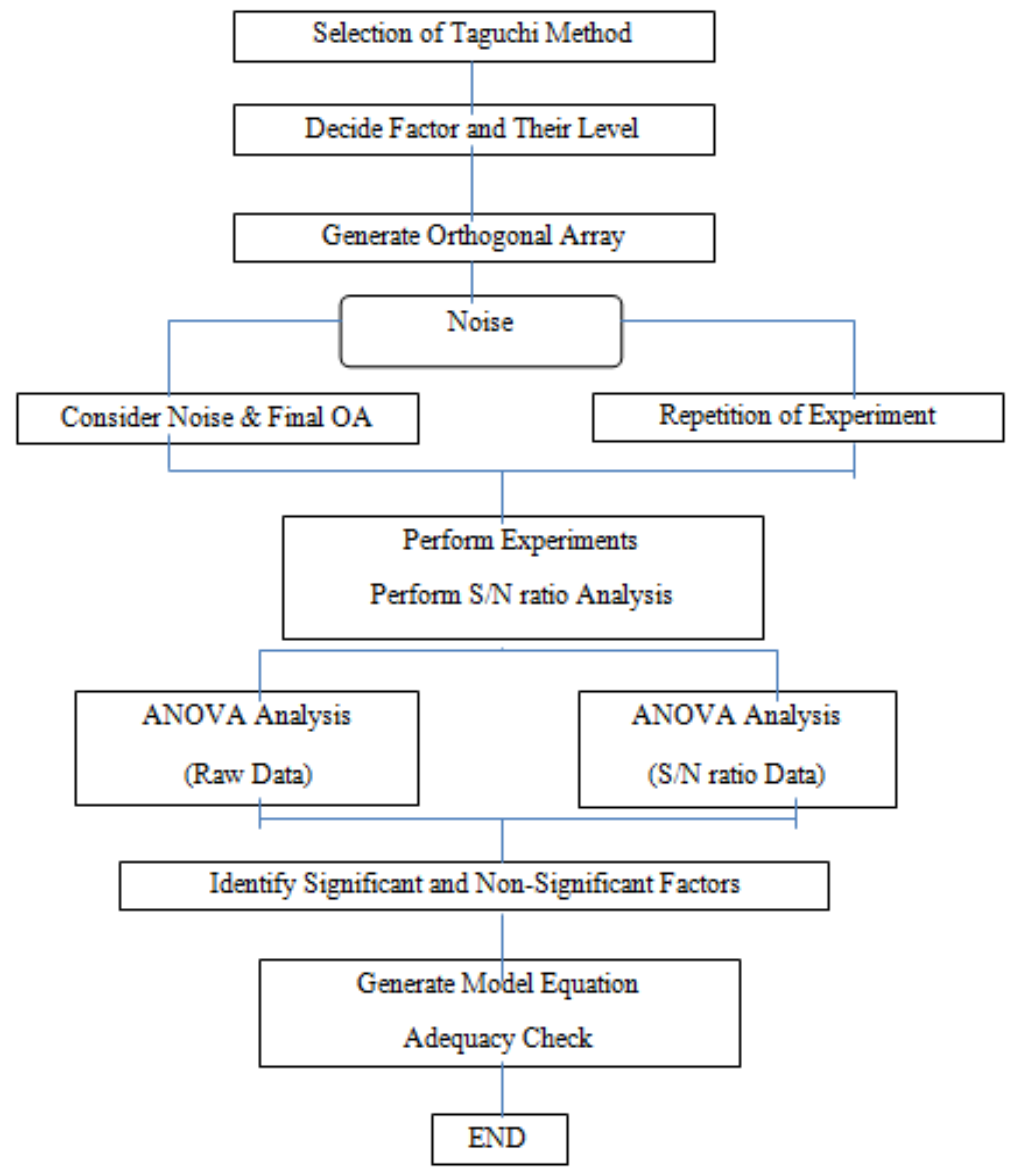

Figure 4.Flow Diagram of present research work

In show inquire about work two diverse DOE techniques were embraced for test work, so factors were chosen for Taguchi strategy and RSM procedure and present in this segment of research work. It's a powerful statistical technique which assists in studying multiple variables and in maximization of learning using a minimum of resources. The effects of process parameters were studied by various researchers from last decades. It is very difficult to design, experiments for any type of research and here a scientific approach is helpful for researchers which is known as "DESIGN OF EXPERIMENT".[7]

Taguchi suggests orthogonal cluster (OA) for laying out of investigations. These OA"s are summed up Graeco-Latin squares. To outline an examination is to choose the most reasonable $\mathrm{OA}$ and to dole out the parameters and communications important to the fitting segments. The utilization of direct diagrams and triangular tables proposed by Taguchi makes the task of parameters straightforward. The exhibit drives all experimenters to plan practically indistinguishable investigations (Roy, 1990). Total 16 experiments are show in table 2.[8]

Table 1. Levels and factors

\begin{tabular}{|c|c|c|}
\hline Process Parameters & Symbol & Range \\
\hline Pulse on time & Ton & $2-10$ \\
\hline Pulse off time & Toff & $2-10$ \\
\hline Peak Current & Current & $4-10$ \\
\hline Wire Feed & WF & $3-10$ \\
\hline
\end{tabular}


International Journal of Recent Advances in Mechanical Engineering (IJMECH) Vol.7, No.3, August 2018

Table 2. L16 orthogonal array

\begin{tabular}{|c|c|c|c|c|}
\hline Sr. No. & Ton & Toff & feed & Current \\
\hline 1 & 4 & 4 & 3 & 2 \\
\hline 2 & 4 & 6 & 5 & 4 \\
\hline 3 & 4 & 8 & 7 & 6 \\
\hline 4 & 4 & 10 & 9 & 8 \\
\hline 5 & 6 & 4 & 5 & 6 \\
\hline 6 & 6 & 6 & 3 & 8 \\
\hline 7 & 6 & 8 & 9 & 2 \\
\hline 8 & 6 & 10 & 7 & 4 \\
\hline 9 & 8 & 4 & 7 & 8 \\
\hline 10 & 8 & 6 & 9 & 6 \\
\hline 11 & 8 & 8 & 3 & 4 \\
\hline 12 & 8 & 10 & 5 & 4 \\
\hline 13 & 10 & 4 & 9 & 2 \\
\hline 14 & 10 & 6 & 7 & 8 \\
\hline 15 & 10 & 8 & 5 & \\
\hline 16 & 10 & 10 & 3 & \\
\hline
\end{tabular}

Response surface philosophy (RSM) is a gathering of numerical and factual systems valuable for examining issues in which a few free factors impact a needy variable or reaction, and the objective is to streamline this reaction. In numerous trial conditions, it is conceivable to speak to autonomous factors in quantitative frame as given in Equation. At that point these variables can be thought of as having a useful association with reaction as takes after:

$$
\mathrm{Y}=\emptyset\left(\mathrm{X}_{1}, \mathrm{X}_{2}, \cdots \cdots \cdots \cdots \cdots \cdots \cdots \cdots \cdots, \mathrm{X}_{\mathrm{K}}\right) \pm \mathrm{e}_{\mathrm{t}}
$$

For the present work, RSM has been connected for building up the scientific models as different relapse conditions for the quality normal for machined parts created by WEDM process. In applying the reaction surface procedure, the needy variable is seen as a surface to which a numerical model is fitted.

Table 3. Design matrix for present study using RSM method

\begin{tabular}{|c|c|c|c|c|c|c|}
\hline RunOrder & PtType & Blocks & Ton & Toffi & Feed & Current \\
\hline 1 & 0 & 1 & 7 & 7 & 6 & 5 \\
\hline 2 & 2 & 1 & 10 & 4 & 6 & 5 \\
\hline 3 & 0 & 1 & 7 & 7 & 6 & 5 \\
\hline 4 & 2 & 1 & 7 & 4 & 6 & 8 \\
\hline 5 & 2 & 1 & 7 & 10 & 9 & 5 \\
\hline 6 & 2 & 1 & 10 & 10 & 6 & 5 \\
\hline 7 & 2 & 1 & 10 & 7 & 3 & 5 \\
\hline 8 & 2 & 1 & 4 & 7 & 3 & 5 \\
\hline 9 & 2 & 1 & 10 & 7 & 6 & 2 \\
\hline 10 & 2 & 1 & 10 & 7 & 9 & 5 \\
\hline 11 & 2 & 1 & 7 & 7 & 9 & 8 \\
\hline 12 & 2 & 1 & 4 & 7 & 9 & 5 \\
\hline 13 & 2 & 1 & 7 & 4 & 9 & 5 \\
\hline 14 & 0 & 1 & 7 & 7 & 6 & 5 \\
\hline 15 & 2 & 1 & 7 & 4 & 6 & 2 \\
\hline 16 & 2 & 1 & 4 & 7 & 6 & 2 \\
\hline 17 & 2 & 1 & 4 & 10 & 6 & 5 \\
\hline 18 & 2 & 1 & 10 & 7 & 6 & 8 \\
\hline 19 & 2 & 1 & 7 & 10 & 3 & 5 \\
\hline 20 & 2 & 1 & 7 & 7 & 9 & 2 \\
\hline 21 & 2 & 1 & 4 & 7 & 6 & 8 \\
\hline 22 & 2 & 1 & 7 & 10 & 6 & 8 \\
\hline 23 & 2 & 1 & 4 & 4 & 6 & 5 \\
\hline 24 & 2 & 1 & 7 & 7 & 3 & 8 \\
\hline 25 & 2 & 1 & 7 & 7 & 3 & 2 \\
\hline 26 & 2 & 1 & 7 & 4 & 3 & 5 \\
\hline 27 & 2 & 1 & 7 & 10 & 6 & 2 \\
\hline
\end{tabular}




\section{RESUlt AND DiscuSSION}

All experiments were designed according to taguchi and RSM technique, which were presented in table 2 and table 3. Experimental results in term of cutting time and cutting rate is presented in table. Main outcomes focused in this study are following: [SN ratio methodology, ANOVA Analysis, Model equations generation and MOGA approach ].

\subsection{EXPERIMENTAL RESUlts For TAGUCHI METHOD}

In present study WEDM experiments were performed using orthogonal array design experiment table made by taguchi method for square shape work piece material. Response characteristics are selected by literature review. Selected orthogonal array were present in table 2 .

The experimental results for cutting time (CT) and cutting rate (CR) are given in Table 4. 16 experiments were conducted using Taguchi experimental design methodology and each experiment was simply repeated three times for obtaining proper $\mathrm{S} / \mathrm{N}$ values. Minitab software was used to carry out all results.

Table 4. Experimental Results of Cutting Time and Cutting rate

\begin{tabular}{|c|c|c|c|c|c|c|c|c|}
\hline \multirow{2}{*}{ Trial } & \multicolumn{3}{|c|}{ Cutting Time $(\mathrm{sec})$} & \multirow{2}{*}{ S/N Ratio } & \multicolumn{3}{c|}{ Cutting Rate $(\mathrm{mm} / \mathrm{sec})$} & S/N \\
\cline { 2 - 5 } & T1 & T2 & T3 & & T1 & T2 & T3 & Ratio \\
\hline 1 & 151.243 & 151.692 & 151.700 & -43.61 & 0.375 & 0.376 & 0.383 & -8.45 \\
\hline 2 & 151.684 & 150.537 & 151.715 & -43.59 & 0.380 & 0.375 & 0.385 & -8.40 \\
\hline 3 & 151.246 & 151.181 & 151.614 & -43.59 & 0.379 & 0.381 & 0.385 & -8.36 \\
\hline 4 & 150.439 & 150.239 & 151.605 & -43.56 & 0.380 & 0.380 & 0.389 & -8.33 \\
\hline 5 & 151.127 & 151.658 & 151.493 & -43.60 & 0.376 & 0.375 & 0.377 & -8.49 \\
\hline 6 & 150.066 & 150.199 & 152.171 & -43.56 & 0.372 & 0.370 & 0.383 & -8.52 \\
\hline 7 & 151.597 & 151.649 & 151.989 & -43.62 & 0.385 & 0.384 & 0.391 & -8.25 \\
\hline 8 & 151.246 & 151.381 & 151.915 & -43.60 & 0.384 & 0.381 & 0.390 & -8.29 \\
\hline 9 & 151.251 & 150.973 & 152.702 & -43.61 & 0.373 & 0.372 & 0.385 & -8.48 \\
\hline 10 & 151.536 & 151.649 & 151.876 & -43.61 & 0.379 & 0.376 & 0.385 & -8.40 \\
\hline 11 & 151.843 & 151.247 & 151.038 & -43.60 & 0.381 & 0.382 & 0.389 & -8.31 \\
\hline 12 & 151.368 & 151.612 & 152.087 & -43.61 & 0.381 & 0.382 & 0.395 & -8.27 \\
\hline 13 & 152.191 & 152.547 & 152.306 & -43.65 & 0.376 & 0.378 & 0.386 & -8.40 \\
\hline 14 & 151.816 & 152.286 & 153.100 & -43.65 & 0.383 & 0.382 & 0.385 & -8.32 \\
\hline 15 & 151.117 & 150.721 & 152.440 & -43.60 & 0.376 & 0.378 & 0.381 & -8.44 \\
\hline 16 & 150.317 & 151.040 & 152.384 & -43.59 & 0.378 & 0.379 & 0.388 & -8.36 \\
\hline
\end{tabular}

\section{EFFECT ON CUTTING Time}

Effect of process parameters on cutting time of test piece were present in this section. Outcome of taguchi method for $\mathrm{S} / \mathrm{N}$ ration data were show in figure 5 and figure 6 for $\mathrm{CT}$ response. It must be clear that the machine used for experimental work was quite old and have some overwhelming issues with it, but due to lack of availability new machine, all experiments were performed on this machine with all safety and research measures to get proper results.

It was shown in figure 4 that Ton and current factors show more effect on CT response than other variables (factors) of WEDM machine. The results were changed with other research work and the reason was machine condition and its make year. S/N ratio was selected smaller is better because minimum time for cut was desirable for WEDM machining process 
International Journal of Recent Advances in Mechanical Engineering (IJMECH) Vol.7, No.3, August 2018

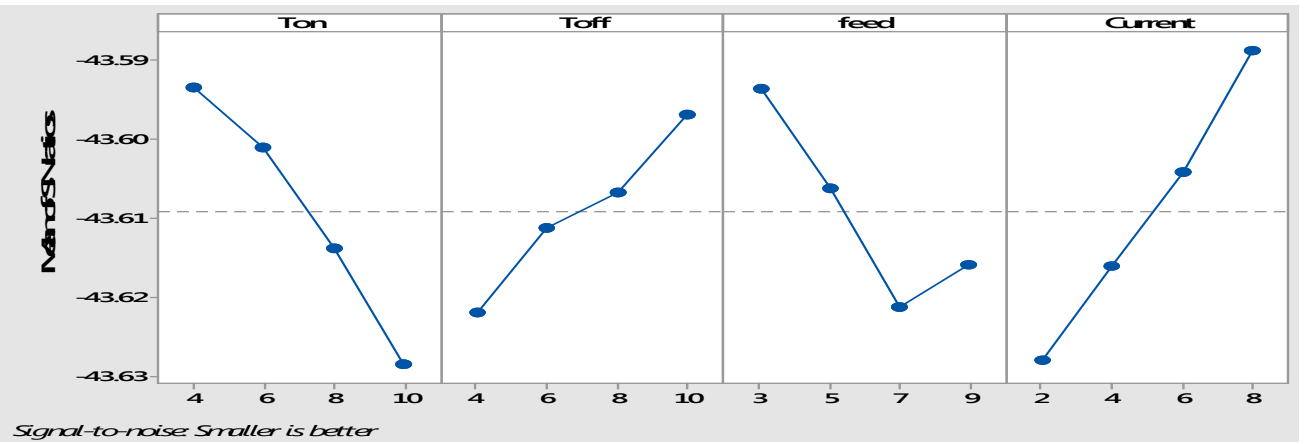

Figure 5.Effects of Process Parameters on Cutting time (S/N Data).

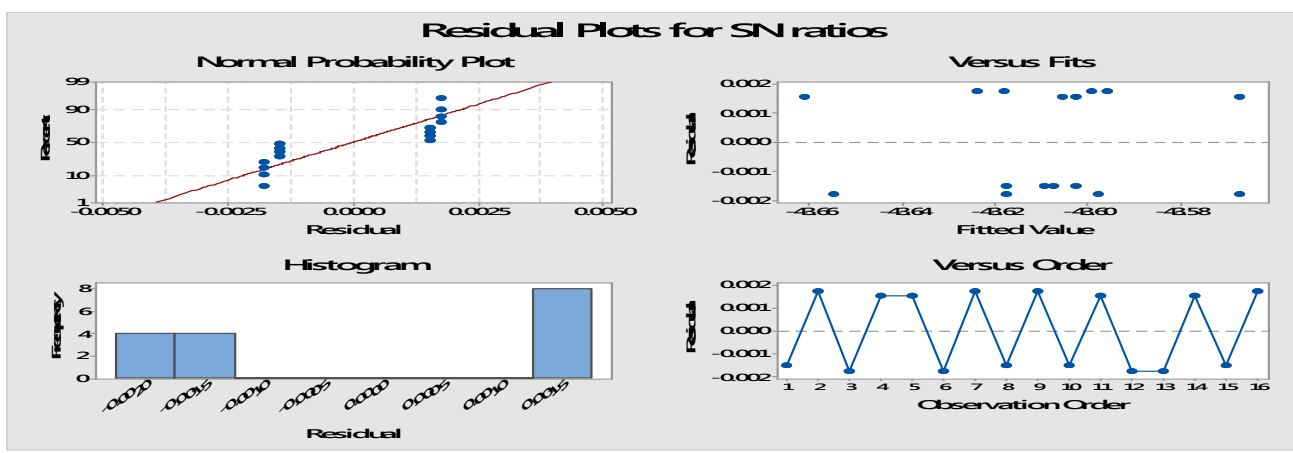

Figure 6.Residual Plots for Cutting time (S/N ratio)

Residual plots were also present in this section for selected responses to identify the problems like non normality, non-random variation, non-constant variance, higher-order relationships, and outliers.These residuals plots were show in figure 6 for $\mathrm{S} / \mathrm{N}$ ratio data for response CT. Points will not follow the straight line of normal probability which means residuals were less normal distributed for this response variable. The reason was data collection on the machine and some errors present in machine. Since residuals exhibit no clear pattern, there is no error due to time or data collection order

It was found that no single factor was non-significant which means all variables were significant for present response CT. if any factor was treat as non-significant variable, then it was pooled from calculation part of ANOVA.

Table 5. Analysis of Variance for Cutting Time (S/N ratio Data)

\begin{tabular}{|l|l|l|l|l|l|l|}
\hline Source & DF & Seq. SS & Adj SS & Adj MS & F & P \\
\hline Ton & 3 & 0.002855 & 0.002855 & 0.000952 & 65.63 & 0.003 \\
\hline Toff & 3 & 0.001299 & 0.001299 & 0.000433 & 29.87 & 0.010 \\
\hline Feed & 3 & 0.001765 & 0.001765 & 0.000588 & 40.57 & 0.006 \\
\hline Current & 3 & 0.003386 & 0.003386 & 0.001129 & 77.83 & 0.002 \\
\hline $\begin{array}{l}\text { Residual } \\
\text { Error }\end{array}$ & 3 & 0.000044 & 0.000044 & 0.000015 & & \\
\hline Total & 15 & 0.009349 & & & & \\
\hline
\end{tabular}

DF - degrees of freedom, SS - sum of squares, MS - mean squares(Variance), F-ratio of variance of a source to variance of error, $\mathrm{P}<0.05$ - determines significance of a factor at $95 \%$ confidence level 
Best part of Taguchi method was response table's generation for raw data and S/N ratio data, which gives rank of factor as per response variable. So in this section response tables were present for raw and $\mathrm{S} / \mathrm{N}$ ratio data in table 5.The rank was generated by delta of $\mathrm{S} / \mathrm{N}$ ratio and mean data of selected response variable. Minitab software was used to assign this task for present study. As per table 6 current was most critical ranked factor for selected response, whereas Toff was least ranked factor to effect the selected response. Ton was second ranked and feed of wire was third rank among all factors.

Table 6. Response Table for Cutting Time

\begin{tabular}{|l|l|l|l|l|}
\hline Level & Ton & Toff & feed & Current \\
\hline 1 & -43.59 & -43.62 & -43.59 & -43.63 \\
\hline 2 & -43.60 & -43.61 & -43.61 & -43.62 \\
\hline 3 & -43.61 & -43.61 & -43.62 & -43.60 \\
\hline 4 & -43.63 & -43.60 & -43.62 & -43.59 \\
\hline Delta & 0.04 & 0.03 & 0.03 & 0.04 \\
\hline Rank & $\mathbf{2}$ & $\mathbf{4}$ & $\mathbf{3}$ & $\mathbf{1}$ \\
\hline
\end{tabular}

\section{EFFect On CUTTING RATE (CR)}

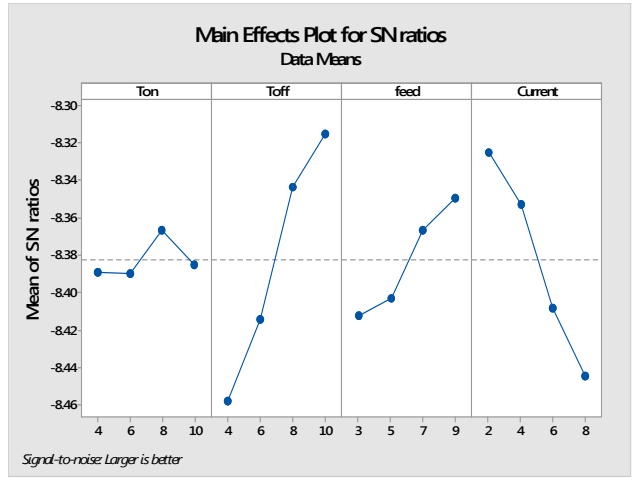

Figure 7: Effects of Process Parameters on CR

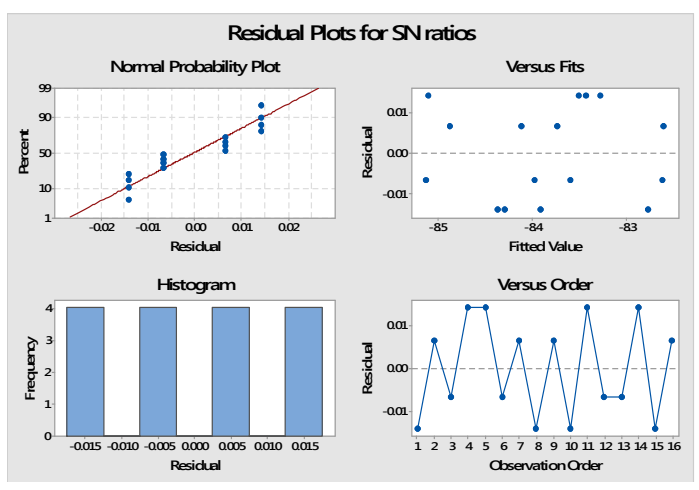

Figure 8. Residual Plots

Residual plots were also present in this section for selected responses to identify the problems like non normality, non-random variation, non-constant variance, higher-order relationships, and outliers. These residuals plots were show in figure 8 for $\mathrm{S} / \mathrm{N}$ ratio data for response CR. Points will not follow the straight line of normal probability which means residuals were less normal distributed for this response variable. The reason was data collection on the machine and some errors present in machine. Since residuals exhibit no clear pattern, there is no error due to time or data collection order.

Table 7. Analysis of Variance for Cutting Rate ( $\mathrm{S} / \mathrm{N}$ ratio Data)

\begin{tabular}{|l|l|l|l|l|l|l|}
\hline Source & DF & Seq SS & Adj SS & Adj MS & F & P \\
\hline Ton & 3 & 0.001430 & 0.001430 & 0.000477 & 0.72 & 0.601 \\
\hline Toff & 3 & 0.050748 & 0.050748 & 0.016916 & 25.72 & 0.012 \\
\hline Current & 3 & 0.010576 & 0.010576 & 0.003525 & 5.36 & 0.101 \\
\hline Residual Error & 3 & 0.034772 & 0.034772 & 0.011591 & 17.62 & 0.021 \\
\hline Residual Error & 3 & 0.001973 & 0.001973 & 0.000658 & & \\
\hline Total & 15 & 0.099500 & & & & \\
\hline
\end{tabular}


International Journal of Recent Advances in Mechanical Engineering (IJMECH) Vol.7, No.3, August 2018

Table 8. Response Table for Cutting Rate (S/N ratio Data)

\begin{tabular}{|c|c|c|c|c|}
\hline Level & Ton & Toff & feed & Current \\
\hline 1 & -8.389 & -8.458 & -8.412 & -8.325 \\
\hline 2 & -8.390 & -8.414 & -8.403 & -8.353 \\
\hline 3 & -8.367 & -8.344 & -8.367 & -8.408 \\
\hline 4 & -8.385 & -8.315 & -8.349 & -8.445 \\
\hline Delta & 0.023 & 0.143 & 0.063 & 0.120 \\
\hline Rank & $\mathbf{4}$ & $\mathbf{1}$ & $\mathbf{3}$ & $\mathbf{2}$ \\
\hline
\end{tabular}

The rank only indicate the relative importance of each factor, but it means that only factor which has highest rank was most important, was wrong outcome, least rank factor have also importance for study and it was finalized by ANOVA analysis.

\subsection{EXPERIMENTAL RESULTS FOR RSM}

Table 9. Response results for cutting time (CT) and cutting rate (CR)

\begin{tabular}{|c|c|c|c|c|c|c|c|c|}
\hline $\begin{array}{l}\text { Run } \\
\text { Order }\end{array}$ & PtType & Blocks & Ton & Toff & Feed & Current & $\begin{array}{l}\text { Cutting } \\
\text { Time }\end{array}$ & $\begin{array}{l}\text { Cuttin } \\
\text { g Rate }\end{array}$ \\
\hline 1 & 0 & 1 & 7 & 7 & 6 & 5 & 151.828 & 0.326 \\
\hline 2 & 2 & 1 & 10 & 4 & 6 & 5 & 153.378 & 0.337 \\
\hline 3 & 0 & 1 & 7 & 7 & 6 & 5 & 152.352 & 0.328 \\
\hline 4 & 2 & 1 & 7 & 4 & 6 & 8 & 151.575 & 0.344 \\
\hline 5 & 2 & 1 & 7 & 10 & 9 & 5 & 151.722 & 0.342 \\
\hline 6 & 2 & 1 & 10 & 10 & 6 & 5 & 153.111 & 0.347 \\
\hline 7 & 2 & 1 & 10 & 7 & 3 & 5 & 152.975 & 0.323 \\
\hline 8 & 2 & 1 & 4 & 7 & 3 & 5 & 149.946 & 0.361 \\
\hline 9 & 2 & 1 & 10 & 7 & 6 & 2 & 154.883 & 0.379 \\
\hline 10 & 2 & 1 & 10 & 7 & 9 & 5 & 153.762 & 0.342 \\
\hline 11 & 2 & 1 & 7 & 7 & 9 & 8 & 151.380 & 0.356 \\
\hline 12 & 2 & 1 & 4 & 7 & 9 & 5 & 150.868 & 0.342 \\
\hline 13 & 2 & 1 & 7 & 4 & 9 & 5 & 152.320 & 0.324 \\
\hline 14 & 0 & 1 & 7 & 7 & 6 & 5 & 151.941 & 0.344 \\
\hline 15 & 2 & 1 & 7 & 4 & 6 & 2 & 153.206 & 0.365 \\
\hline 16 & 2 & 1 & 4 & 7 & 6 & 2 & 151.381 & 0.349 \\
\hline 17 & 2 & 1 & 4 & 10 & 6 & 5 & 150.680 & 0.319 \\
\hline 18 & 2 & 1 & 10 & 7 & 6 & 8 & 152.950 & 0.342 \\
\hline 19 & 2 & 1 & 7 & 10 & 3 & 5 & 151.704 & 0.312 \\
\hline 20 & 2 & 1 & 7 & 7 & 9 & 2 & 152.991 & 0.342 \\
\hline 21 & 2 & 1 & 4 & 7 & 6 & 8 & 150.155 & 0.364 \\
\hline 22 & 2 & 1 & 7 & 10 & 6 & 8 & 150.547 & 0.354 \\
\hline 23 & 2 & 1 & 4 & 4 & 6 & 5 & 150.987 & 0.360 \\
\hline 24 & 2 & 1 & 7 & 7 & 3 & 8 & 151.363 & 0.353 \\
\hline 25 & 2 & 1 & 7 & 7 & 3 & 2 & 153.071 & 0.340 \\
\hline 26 & 2 & 1 & 7 & 4 & 3 & 5 & 151.574 & 0.330 \\
\hline 27 & 2 & 1 & 7 & 10 & 6 & 2 & 153.060 & 0.358 \\
\hline
\end{tabular}




\section{CutTing Time}

In this section RSM technique was used to find significance or non-significance variables for selected response CT. the ANOVA analysis result was present in table 10 for CT response variable. Backward elimination method was applied to remove non-significant factors and their interactions. So only final ANOVA table was present here.

Table 10. ANOVA analysis for CT

\begin{tabular}{|l|l|l|l|l|l|l|l|}
\hline Source & DF & SeqSS & Contribution & Adj SS & Adj MS & F-Value & P-Value \\
\hline Model & 5 & 34.9870 & $95.21 \%$ & 34.9870 & 6.9974 & 83.52 & 0.000 \\
\hline Linear & 4 & 34.5001 & $93.89 \%$ & 34.5001 & 8.6250 & 102.94 & 0.000 \\
\hline Ton & 1 & 24.2037 & $65.87 \%$ & 24.2037 & 24.2037 & 288.88 & 0.000 \\
\hline Toff & 1 & 0.4096 & $1.11 \%$ & 0.4096 & 0.4096 & 4.89 & 0.038 \\
\hline Feed & 1 & 0.4846 & $1.32 \%$ & 0.4846 & 0.4846 & 5.78 & 0.025 \\
\hline Current & 1 & 9.4022 & $25.59 \%$ & 9.4022 & 9.4022 & 112.22 & 0.000 \\
\hline Square & 1 & 0.4869 & $1.33 \%$ & 0.4869 & 0.4869 & 5.81 & 0.025 \\
\hline $\begin{array}{l}\text { Current* } \\
\text { Current }\end{array}$ & 1 & 0.4869 & $1.33 \%$ & 0.4869 & 0.4869 & 5.81 & 0.025 \\
\hline Error & 21 & 1.7595 & $4.79 \%$ & 1.7595 & 0.0838 & & \\
\hline $\begin{array}{l}\text { Lack-of- } \\
\text { Fit }\end{array}$ & 19 & 1.6079 & $4.38 \%$ & 1.6079 & 0.0846 & 1.12 & 0.575 \\
\hline $\begin{array}{l}\text { Pure } \\
\text { Error }\end{array}$ & 2 & 0.1516 & $0.41 \%$ & 0.1516 & 0.0758 & & \\
\hline Total & 26 & 36.7465 & $100.00 \%$ & & & & \\
\hline
\end{tabular}

As shown in table \% contribution of each factor and their interaction was also show for this response variable. Most contributed variable was Ton and one variable Toff was non-significant for CT response.

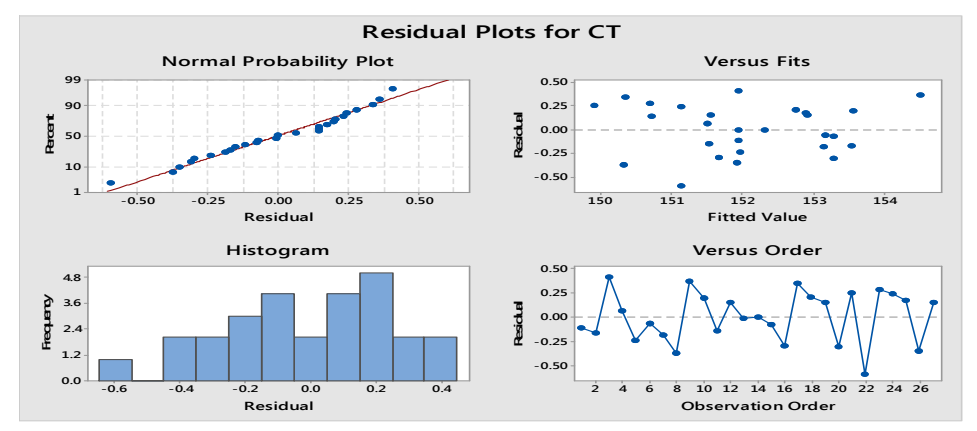

Figure 9. Residual Plots for CT (RSM)

Residual plots were also present in this section for selected responses to identify the problems like non normality, non-random variation, non-constant variance, higher-order relationships, and outliers. These residuals plots was show in figure 9 for RSM data for response CT. Points will follow the straight line of normal probability which means residuals were normal distributed for this response variable. Since residuals exhibit no clear pattern, there is no error due to time or data collection order. 


\section{CutTing RATe (MM/SeC)}

In this section RSM technique was used to find significance or non-significance variables for selected response CR. the ANOVA analysis result was present in table 11 for CR response variable. Backward elimination method was applied to remove non-significant factors and their interactions. So only final ANOVA table was present here.

Table 11. ANOVA analysis for CR

\begin{tabular}{|l|l|l|l|l|l|}
\hline Source & DF & Adj SS & AdjMS & F-Value & P-Value \\
\hline Model & 6 & 0.009935 & 0.001656 & 295.01 & 0.000 \\
\hline Linear & 4 & 0.009875 & 0.002469 & 439.81 & 0.000 \\
\hline Ton & 1 & 0.009666 & 0.009666 & 1722.08 & 0.000 \\
\hline Toff & 1 & 0.000079 & 0.000079 & 14.08 & 0.001 \\
\hline Feed & 1 & 0.000066 & 0.000066 & 11.70 & 0.003 \\
\hline Current & 1 & 0.000064 & 0.000064 & 11.41 & 0.003 \\
\hline Square & 2 & 0.000061 & 0.000030 & 5.40 & 0.013 \\
\hline Toff*Toff & 1 & 0.000052 & 0.000052 & 9.31 & 0.006 \\
\hline Feed*Feed & 1 & 0.000018 & 0.000018 & 3.25 & 0.086 \\
\hline Error & 20 & 0.000112 & 0.000006 & & \\
\hline Lack-of-Fit & 18 & 0.000110 & 0.000006 & 5.73 & 0.159 \\
\hline Pure Error & 2 & 0.000002 & 0.000001 & & \\
\hline Total & 26 & & & & \\
\hline
\end{tabular}

As shown in table \% contribution of each factor and their interaction was also show for this response variable. Most contributed variable was Ton and one variable Feed*Feed was nonsignificant for CR response.



Figure 10. Residual Plots for CR (RSM)

Residual plots were also present in this section for selected responses to identify the problems like non normality, non-random variation, non-constant variance, higher-order relationships, and outliers. These residuals plots was show in figure10 for RSM data for response CR. Points will follow the straight line of normal probability which means residuals were normal distributed for this response variable. Since residuals exhibit no clear pattern, there is no error due to time or data collection order. 


\section{REGRESSION EQUATION FOR RESPONSES}

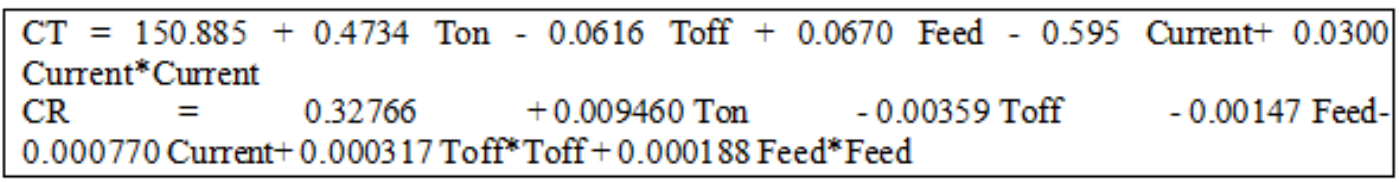

\section{MODEL SUMmaRY}

\begin{tabular}{|l|c|c|c|c|}
\hline & $\mathbf{S}$ & $\mathbf{R}^{\mathbf{2}}$ & $\mathbf{R}^{\mathbf{2}}$ (adj.) & $\mathbf{R}^{\mathbf{2}}$ (pred.) \\
\hline CT & 0.289 & $95.21 \%$ & $94.07 \%$ & $91.93 \%$ \\
\hline CR & 0.0023 & $98.88 \%$ & $98.55 \%$ & $97.90 \%$ \\
\hline
\end{tabular}

\subsection{Multi ObJective Genetic Algorithm (Moga)}

In present study MOGA optimization technique was also applied on regression modeling equations generated by RSM technique for bith responses. Two function developed for these response equation. Function 1 represent cutting time, function 2 represent cutting rate.

After fitness function generation, data was entered into global optimization tools box, which was available in MATLAB software. Solver was selected as per requirement, for present study MOGA was selected as solver. All required data was entered into GUI window for present work. Population size was selected 100 for present study and after this selection of population size solver was run and results was generated.
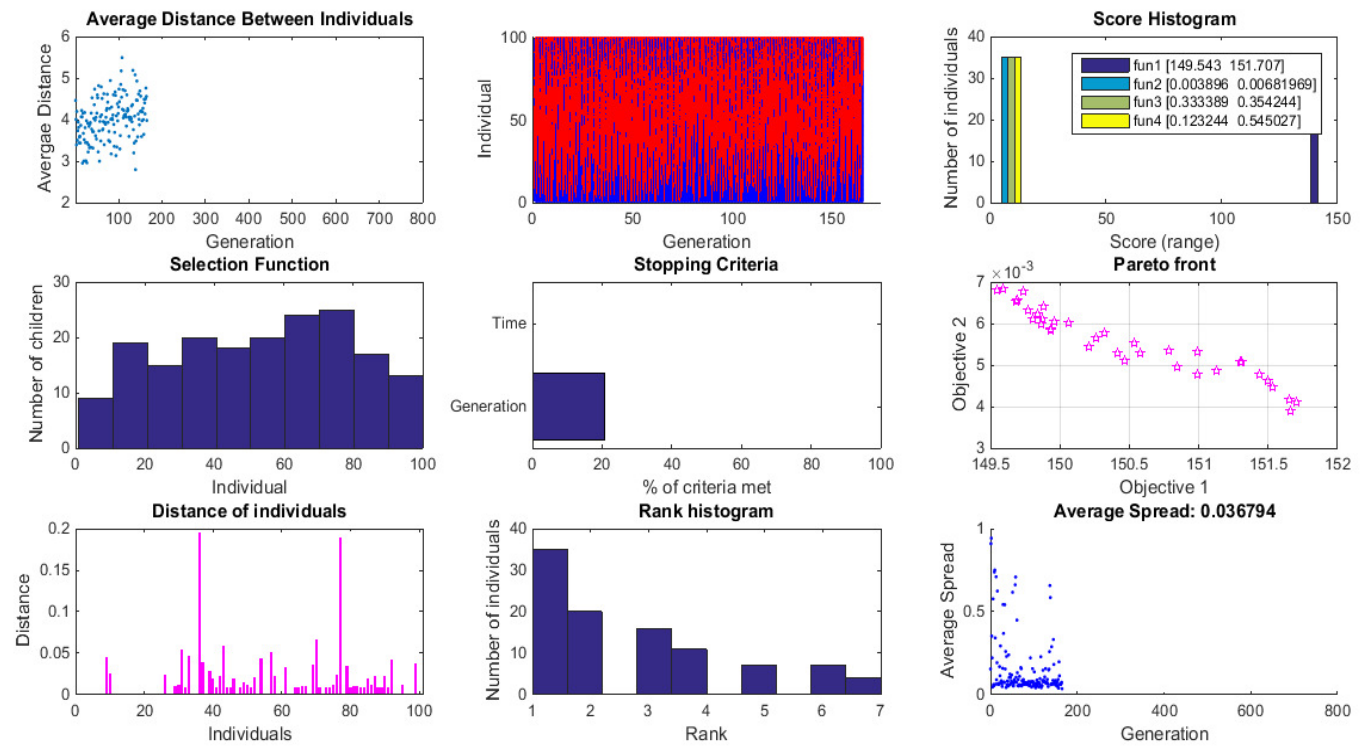

Figure 11. Results from MOGA modeling in MATLAB

All possible results generated during modeling of MOGA technique was present in figure 11. As seen in figure some graphs represent only modeling generation of different parameters, but one graph represent outcome of this MOGA technique, which was named score histogram. Although this technique provide best optimum results for given functions, but in present study, all possible score results with factor values were present in table 12 for consideration. The selection of best case was depends on user and its requirement. Optimum values for Fitness Functions using MOGA (2 fitness function) 
International Journal of Recent Advances in Mechanical Engineering (IJMECH) Vol.7, No.3, August 2018

Table 12. Optimum values for fitness functions and Factor's values for all fitness functions using MOGA

\begin{tabular}{|l|l|l|l|}
\hline $\mathrm{f} 1$ & $\mathrm{f} 2$ & $\mathrm{x} 1$ & $\mathrm{x} 2$ \\
\hline 151.66 & 0.35 & 4.00 & 3.00 \\
\hline 149.93 & 0.35 & 4.07 & 3.50 \\
\hline 149.54 & 0.33 & 4.01 & 3.18 \\
\hline 149.59 & 0.33 & 4.01 & 3.85 \\
\hline 150.99 & 0.35 & 4.39 & 3.21 \\
\hline 149.77 & 0.34 & 4.01 & 3.51 \\
\hline 151.65 & 0.35 & 4.07 & 3.18 \\
\hline 151.44 & 0.34 & 4.05 & 3.11 \\
\hline 149.86 & 0.35 & 4.03 & 3.33 \\
\hline 150.47 & 0.35 & 4.03 & 3.11 \\
\hline 150.78 & 0.34 & 4.08 & 3.38 \\
\hline 151.71 & 0.35 & 4.22 & 3.45 \\
\hline 151.13 & 0.35 & 4.06 & 3.26 \\
\hline 150.58 & 0.34 & 4.02 & 3.29 \\
\hline 150.32 & 0.34 & 4.02 & 3.25 \\
\hline 149.89 & 0.34 & 4.14 & 3.68 \\
\hline 149.96 & 0.34 & 4.01 & 3.67 \\
\hline 150.21 & 0.35 & 4.09 & 3.17 \\
\hline 149.94 & 0.35 & 4.08 & 3.15 \\
\hline 149.88 & 0.34 & 4.03 & 3.53 \\
\hline 150.26 & 0.34 & 4.01 & 3.44 \\
\hline 150.06 & 0.34 & 4.05 & 3.48 \\
\hline 150.42 & 0.35 & 4.26 & 3.46 \\
\hline 149.81 & 0.34 & 4.00 & 3.05 \\
\hline 150.99 & 0.34 & 4.06 & 3.90 \\
\hline 151.30 & 0.34 & 4.09 & 3.42 \\
\hline 149.84 & 0.34 & 4.02 & 3.91 \\
\hline 151.50 & 0.35 & 4.06 & 3.00 \\
\hline 149.74 & 0.34 & 4.23 & 3.35 \\
\hline 149.69 & 0.34 & 4.04 & 3.23 \\
\hline 151.53 & 0.35 & 4.12 & 3.80 \\
\hline 150.54 & 0.34 & 4.02 & 3.41 \\
\hline 150.84 & 0.35 & 4.35 & 3.25 \\
\hline 149.69 & 0.34 & 4.02 & 3.31 \\
\hline 151.31 & 0.34 & 4.09 & 3.14 \\
\hline & & & \\
\hline
\end{tabular}

\section{CONCLUSIONS}

1. Model equations for response cutting time and cutting rate was predict accurately with Minitab software and show above $90 \%$ good prediction for responses and can be used by any cutting based machining process manufacture. 
2. Optimization of model equations was performed for all four response equations using MOGA technique; it was useful to predict the role of optimum solution for WEDM machining process. In different practical applications, values of the process parameters can be controlled better if the process models are employed in different industrial applications

\section{REFERENCES}

[1] DebabrataMandal, Surjya k. Pal, ParthaSaha, (2007), Modeling of EDM process using back propagation neural network and multi-objective optimization using non-domination sorting genetic algorithm-II, Journal of materials processing Technology,186, 154-172

[2] PujariSrinivasaRao , KoonaRamji, BeelaSatyanarayana, (2016) ,Effect of wire EDM conditions on generation of residual stresses in machining of aluminum 2014 T6 alloy, Alexandria Engineering Journal, 55,1077-1084

[3] ShivkantTilekar, SankhaShuvra Das, P.K. Patowari ,2014, "Process Parameter Optimization of Wire EDM on Aluminum and Mild steel by Using Taguchi Method" International Conference on Advance in Manufacturing and Materials engineering, AMME 2577-2584

[4] J.R. Gamage, A.K.M. DeSilva , 42 ( 2016 ) , Effect of wire breakage on the process energy utilisation of EDM, 18th CIRP Conference on Electro Physical and Chemical Machining (ISEM XVIII) ,Procedia CIRP 586 - 590

[5] Natarajan, N. and Arunachalam, R. M (2011), Optimization of Micro-EDM with multiple performances characteristics using Taguchi method and Greyrelation analysis., Journal of Scientific and Industrial Research, 70:500-505.

[6] M. Durairaj, D. Sudharsun, N. Swamynathan, ( 2013 ), Analysis of Process Parameters in Wire EDM with Stainless Steel using Single Objective Taguchi Method and Multi Objective Grey Relational Grade, International Conference On DESIGN AND MANUFACTURING, IConDM 2013, Procedia Engineering $64868-877$

[7] RavindranadhBobbili, V. Madhu, A.K. Gogia, (2015) ,Multi response optimization of wire-EDM process parameters of ballistic grade aluminum alloy, Engineering Science and Technology, an International Journal 18 720-726

[8] Tsai, H.C., Yan, B.H. and Huang, F.Y., 2003. EDM performance of Cr/Cu-based composite electrodes. International Journal of Machine Tools and Manufacture, 43(3), 245-252.

[9] NeerajSharma , Rajesh Khanna, Rahul Dev Gupta, (2015)" WEDM process variables investigation for HSLA by response surface methodology and genetic algorithm" Engineering Science and Technology, an International Journal 18, 171-177

[10] Lee, S.H. and Li, X.P., 2001. Study of the effect of machining parameters on the machining characteristics in electrical discharge machining of tungsten carbide. Journal of Materials Processing Technology, 115(3), 344-358.

[11] K.M. Patel, P.M. Pandey, P.V. Rao, (2009) , Surface integrity and material removal mechanisms associated with the EDM of Al2O3 ceramic composite, International Journal of Refractory Metals and Hard Materials 27, 892-899.

[12] Kuriachen Basil, Josephkunju Paul and JeojuM.Issac, (2013), "Spark Gap Optimization of WEDM Process on Ti6Al4V", International Journal of Engineering Science and Innovative Technology (IJESIT) 2(1), 364-369

[13] C.D. Shah, J.R.Mevada and B.C.Khatri , (2013)., “Optimization of Process Parameter of Wire Electrical Discharge Machine by Response Surface Methodology on Inconel-600", International Journal of Emerging Technology and Advanced Engineering, 3(4), 2250- 2459 